\title{
Study on Performance Evaluation of Ecological Environment in the Construction of Index System of Economic Responsibility Audit JINPING XIAO
}

\author{
China West Normal University, Nanchong, 637000, China \\ 40347544@qq.com
}

Keywords: Environmental performance audit; evaluation index system

\begin{abstract}
Environmental performance audit has become an effective management tool for environmental management. In this paper, it takes the concept of ecological environment and ecological environment performance evaluation as the breakthrough point, combined with the evaluation criteria of government environmental performance audit, as well as government environmental performance audit, discussing the construction of the performance audit evaluation index system of environmental protection special fund, as well as its objectives.
\end{abstract}

\section{Introduction}

From the view of the world, the development of environmental performance audit has been developed for nearly fifty years, many developed countries have basically completed the transformation from the traditional environmental audit to the environmental performance audit, the ecological environment performance audit has become an effective management tool for the government departments to carry out environmental management. Different from the traditional audit, the performance audit of the ecological environment can play its role through the audit and supervision of the government's environmental protection special funds utilization as well as the work efficiency of the relevant departments of the government, in this way, the government invested in the limited financial and human resources, it still can get better ecological environment protection benefits and effect.

\section{The Meaning of Ecological Environment Performance}

In this paper, the so called ecological environment performance refers to the achievements such as the government's environmental management, environmental protection, pollution control and recycling of resources and other aspects of the ecological environment protection, including the government's contribution to the whole society's environmental protection.[1]

\section{The Meaning of Performance Evaluation of Ecological Environment}

The performance evaluation of ecological environment refers to the environmental audit factors of the organization can decide whether to implement the environmental objectives.[2] It aims to provide the management with the objective and verifiable information to determine whether the environmental performance can meet the standards set by the management authority, so as to improve environmental performance.[3]

\section{Evaluation Criteria of Government Environmental Performance Audit}

During the process of government environmental performance audition, the audit unit or project should be made with a specific evaluation, you need to have a benchmark for comparison, which is called as the evaluation criteria. The evaluation standard of government environmental performance audit is a kind of scale, which is also the basic requirement of environmental and efficiency of audit object, it is the conclusion drew by the auditing staff. Therefore, making a scientific development of environmental performance audit with strict feasible evaluation criteria is the premise of 
environmental performance audit, which is also the basis for ensuring the quality of audition.

\section{Government Environmental Performance Audit}

Environmental protection special funds performance audit is the product of public accountability content development, environmental protection special funds are the special funds for environmental protection, according to public trust theory, the social public can be acted as the principal, while the government departments (environmental protection special fund) can act as trustee, environmental protection special funds department can accept the social public trust management with special funds, which can have the responsibility of optimizing environmental protection special funds management, making it play its biggest benefits, so as to meet the social public interest and meet the public requirement of setting up good environment.[4]

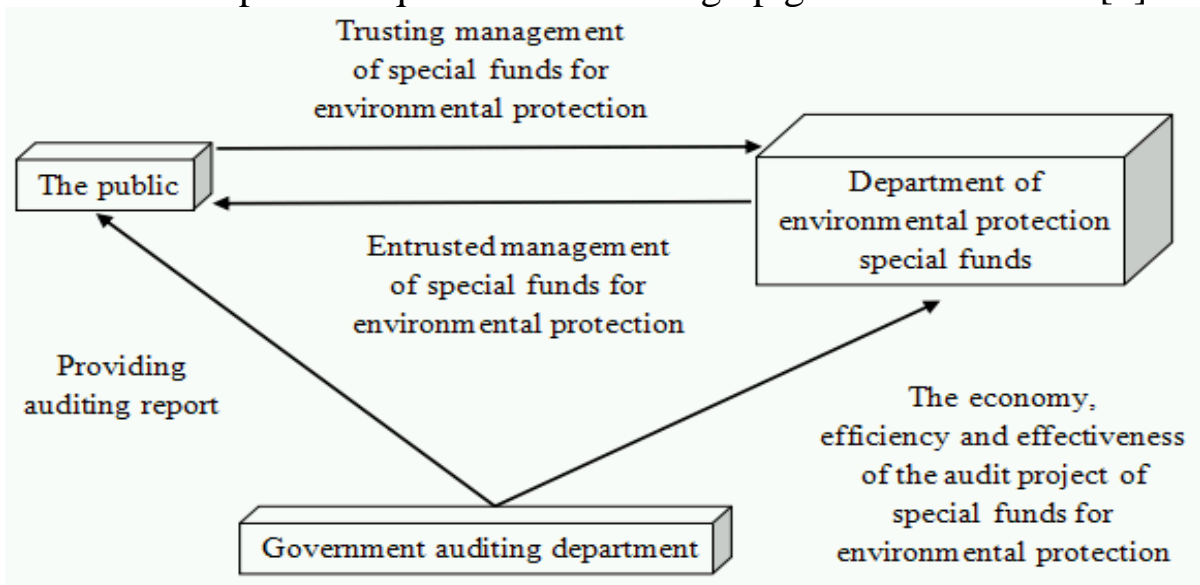

Fig1 Three Party Relationship of Performance Audit of Environmental Protection Special Funds

The objective of performance audit for special environmental protection funds, as well as the subject and object of audit, evaluation index, evaluation criteria and evaluation results these elements can interact with each other, having mutual influence on each other, see Fig. 2. In Fig. 2, we can see that the main auditing body (Government Auditing Department) can have audition and evaluation according to the audit objectives (economy, efficiency, effectiveness, including environmental and equity) on the audit object (special environmental protection funds projects) to have audit evaluation, according to the specific evaluation criteria, with the evaluation criteria and evaluation method, so as to get the environmental protection special funds project performance with auditing evaluation results at last. Among these seven factors, the key factors include evaluation index, evaluation criteria and evaluation method, therefore, the evaluation index system of environmental protection special funds of performance audit evaluation index system is not just a list of evaluation index, but also is the evaluation criteria for each evaluation index.

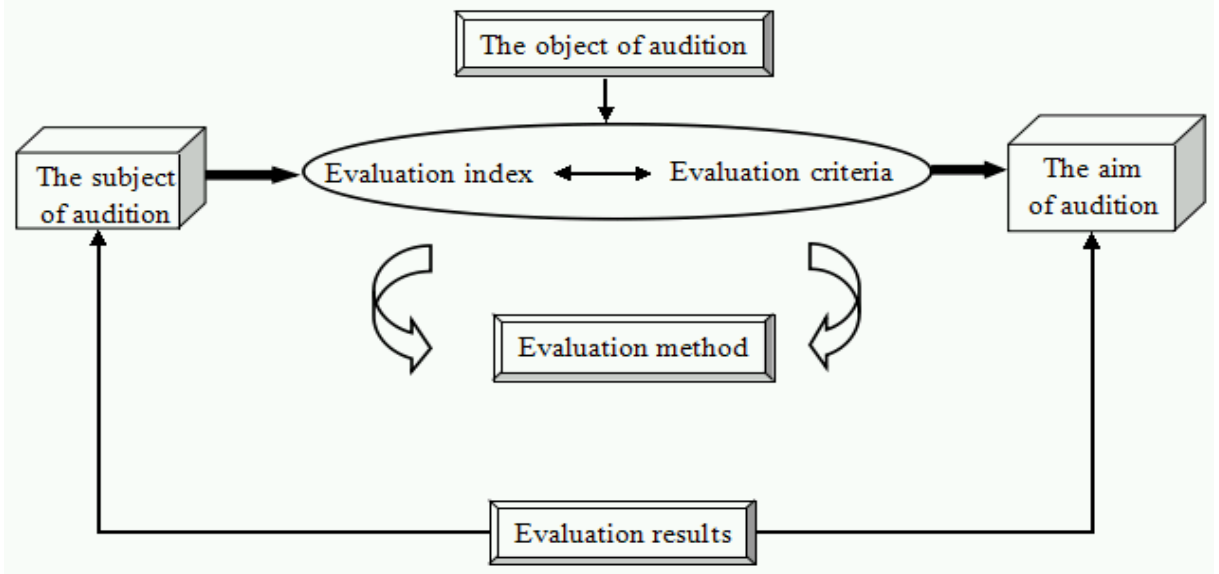

Fig.2 Performance Audit Evaluation of Environmental Protection Special Funds 


\section{The Construction of performance Audit Evaluation Index System of Special Environmental Protection Funds}

Under the support of public accountability theory, the sustainable development theory as well as the system theory, the evaluation index system of environmental protection special fund performance audit can be constructed followed by the following ideas: (1) the public accountability theory and the sustainable development theory can decide the objectives of of environmental protection special funds performance audit. (2)the characteristics of environmental protection special funds and the aim of environmental protection special funds performance audit can determine the feature of the performance evaluation of special environmental protection funds; (3) analyzing the features of special environmental protection funds performance audit evaluation and the problems existed in the evaluation index system of the current environmental protection special fund performance audit. (4) under the support of the system theory, it construct the evaluation index system of environmental protection special fund performance audit.

\section{The Basic Principle of PSR Conceptual Framework}

The evaluation model of government environmental performance audit in this paper is based on PSR framework. PSR concept framework is the model of "Press-State-Response", which is shorted for PSR. It was began in the 1970's, which was first used by the Canadian government to study the economic budget and environmental protection of the government. The framework is clear, and the index can cover all aspects, which is consisted by pressure index, state index and response index. PSR conceptual framework, which is the result of cause and effect of "Press-State-Response", which can explain the human's most basic way of thinking: human beings obtain resources and energy in order to develop their own natural resources and energy. It is inevitable to put some pressure on nature, which can make the natural state change, reducing the resources of nature and bring the deterioration to the nature, therefore, people must take necessary actions to struggle with these changes. Thus, PSR conceptual framework can explain the reason that " why it can occur the changes--what kind of changes has occurred--what should we do". As for the specific application of government environmental performance audit, PRS conceptual framework is using the three dimensions, namely, from pressure, state and response, combined with the reality of the related professional knowledge and index data that can be obtained to determine the required evaluation index, as well as the interpretation of each evaluation index. Thus, the index has strong logic relationship with each other, having interaction with each other, so as to constitute a circulation mechanism.[5]

\section{The Aim of Environmental Protection Special Funds Performance Audit}

Through the analysis of the above theoretical basis, according to the theory of public accountability, the aim of environmental protection special fund performance audit should include the economic feature, as ell as the feature of efficiency and effectiveness. According to the theory of sustainable development, the aim of environmental protection special funds performance audit should also include fairness and environmental protection feature. We can summarize the five goals of the environmental protection special funds performance audit, which can be divided into the goal of economy, efficiency and effectiveness, among them, the goal of effectiveness can include fairness and environmental protection in addition to the traditional sense of effectiveness.

\section{Reference}

[1] International Chamber of Commerce. 1991. An ICC Guide to Effective Environmental Auditing, ICC Publishing, Paris.

[2] LI Shan-mei,CHEN Jia-wen1.Apr.Performance Auditing Evaluation of Environmental Projects Based on PSR Concept,RESOURCES \&INDUSTRIES,2011,Vol.13.2. 
[3] Yan Wei.Definition and connotation of environment,ecology and resource audit[J].Resources \& Industries,2013,15(1) : 136-140

[4] Nola Buhr. A structural View On the Initiation of Environmental Reports, Critical Perspectives on Accounting, 2002,vol.3, pp37-43..

[5] INTOSAI Working Group on Environmental Auditing .Guid-ance on conducting Audits of Activities with an Environmental Perspective[R]2001.

[6] Christopher Po Uitt.Performance Audit in Western Europe: Trends and Choices. Critical Perspectives On Accounting,2003,pp:46-57. 